\title{
Are parents' views about their child's treatment for juvenile idiopathic arthritis (JIA) related to evaluations of their child's quality of life (QoL)? - SPARKS CHARM study K Mulligan*1, A Etheridge ${ }^{2}$, L Kassoumeri², P Woo², LR Wedderburn ${ }^{2}$ and S Newman ${ }^{1}$
}

\author{
Address: ${ }^{1}$ Centre for Behavioural \& Social Sciences in Medicine, University College London, London, UK and ${ }^{2}$ Rheumatology Unit, Institute of \\ Child Health, UCL, London, UK \\ * Corresponding author
}

\author{
from I5th Paediatric Rheumatology European Society (PreS) Congress \\ London, UK. 14-17 September 2008 \\ Published: 15 September 2008 \\ Pediatric Rheumatology 2008, 6(Suppl I):PI67 doi:I0.II86/I546-0096-6-SI-PI67
}

This abstract is available from: http://www.ped-rheum.com/content/6/SI/PI67

(c) 2008 Mulligan et al; licensee BioMed Central Ltd.

\section{Background}

Children with JIA experience impaired QoL. Although treatment with methotrexate (MTX) has been found to improve QoL, some children experience difficulties in taking it. This study examined the influence of parents' attitudes to MTX and treatments in general on assessment of their child's QoL.

\section{Methods}

Mothers or fathers of 143 children aged $\geq 5$ with JIA, completed questionnaires about general beliefs regarding treatment (Treatment Representations Inventory, subscales - treatment value, concerns, cure and decision satisfaction) and specific beliefs regarding benefits and difficulties in taking MTX. Core outcome variables (COV), except ESR, were used to provide information on disease severity. Data were analysed by correlations followed by multiple linear regression with QoL, assessed by the Child Health Questionnaire (CHQ), as the dependent variable.

\section{Results}

Scores on the CHQ indicated greater impairment on physical (40.2,s.d.14.6) than psychosocial (47.6,s.d.12.2) QoL. Physical QoL was related to all COV (correlations 0.283 to -0.708$)$, parents' views about the benefits of MTX $(\mathrm{r}=0.303, \mathrm{p}<0.001)$, difficulties taking MTX $(\mathrm{r}=-0.334$, $\mathrm{p}<0.001)$, treatment concerns $(\mathrm{r}=-0.459, \mathrm{r}<0.001)$ and beliefs in treatment cure $(r=0.328, p<0.001)$. Psychoso- cial QoL was related to 2 of the COV (CHAQ r $=-0.427, \mathrm{p}$ $<0.001$ and parent global assessment, $\mathrm{r}=-0.429, \mathrm{r}<$ $0.001)$ plus difficulties taking MTX $(\mathrm{r}=-0.217, \mathrm{p}<0.01)$ and treatment concerns $(\mathrm{r}=-0.426, \mathrm{r}<0.001)$. Multivariate analysis indicated that general concerns about treatment made a unique contribution to the explanation of both physical and psychosocial QoL, after controlling for disease severity.

\section{Conclusion}

Parents' concerns about treatment of JIA are important in understanding variability in both physical and psychosocial QoL of their children. 